\title{
MUSCLE STRENGTH TRAINING AND PRESCRIBING IN COMPETITIVE TENNIS PLAYERS: A SYSTEMATIC REVIEW
}

\author{
PRESCRIÇÃO E TREINAMENTO DA FORÇA MUSCULAREM TENISTAS COMPETITIVOS: \\ REVISÃO SISTEMÁTICA
}

PRESCRIPCIÓN Y ENTRENAMIENTO DE LA FUERZA MUSCULAREN TENISTAS COMPETITIVOS: REVISIÓN SISTEMÁTICA

\begin{abstract}
João Marcelo de Queiroz Miranda' (iD (Physical Education Professional)

Luís Felipe Tubagi Polito² (DD (Physical Education Professional)

Roberta Luksevicius Rica² (DD (Physical Education Professional) Maria Luiza de Jesus Miranda² (ID (Physical Education Professional) Danilo Sales Bocalini ${ }^{3}$ (ID (Physical Education Professional) Aylton Figueira Júnior ${ }^{2}$ (D) (Physical Education Professional)

1. Universidade Cidade de São Paulo (UNICID), Sport and Movement Pedagogy Study Group (GEPEM), São Paulo, SP, Brazil. 2. Universidade São Judas Tadeu (USJT), Physical Education Graduate Studies Program, São Paulo, SP, Brazil.

3. Universidade Federal do Espírito Santo (UFES), Physical Education Graduate Studies Program, Vitória, ES, Brazil.
\end{abstract}

\section{Correspondence:}

João Marcelo de Queiroz Miranda Rua Tupi, 38, Olho D'agua, Mairiporã - SP, CEP: 07601-055 jmtreinamento@yahoo.com.br

\begin{abstract}
The application of muscle strength training has been investigated for the development of physical capacities in sports. Although the use of training methods is quite clear, the act of prescribing the external training load is often not properly explained. Grass court, or lawn tennis, is a sport with considerable physical demands and strength training can help player performance. Thus, the aim of this study was to investigate strength training methods and external variables in training programs in competitive tennis players. Considering the findings of this particular study, we found that muscle building workout and plyometrics in combination with exercises designed specifically for the sport (tennis drills) were the most efficient muscle strength training methods for improving different strength manifestations. Level of evidence l; Diagnostic study - Investigation of diagnostic test.
\end{abstract}

Keywords: Exercise; Athletic performance; Tennis; Muscle Strength.

\section{RESUMO}

A aplicação do treinamento de força muscular tem sido investigada para desenvolvimento das capacidades físicas em modalidades esportivas. Embora a utilização dos métodos de treinamento seja bastante clara, a prescrição da carga externa do treinamento muitas vezes não é esclarecida. O tênis de campo é uma modalidade de grande exigência física e o treinamento de força pode auxiliar no rendimento esportivo. Dessa forma, o objetivo do presente estudo consistiu em investigar os métodos de treinamento de força e as variáveis externas em programas de treinamento em tenistas competitivos. Considerando os achados do presente estudo, constatamos que a musculação e a pliometria associados aos exercícios específicos da modalidade (tennis drills) foram os métodos de treinamento de força muscular mais eficientes para melhora das diferentes manifestações de força. Nível de evidência l; Estudo diagnóstico - Investigação de exame para diagnóstico.

Descritores: Exercício; Desempenho atlético; Tênis; Força muscular.

\section{RESUMEN}

La aplicación del entrenamiento de fuerza muscular ha sido investigada para el desarrollo de las capacidades físicas en modalidades deportivas. Aunque la utilización de los métodos de entrenamiento sea bastante clara, la prescripción de la carga externa del entrenamiento a menudo no es esclarecida. El tenis de campo es una modalidad de gran exigencia física y el entrenamiento de fuerza puede auxiliar en el rendimiento deportivo. De esta forma, el objetivo del presente estudio consistió en investigar los métodos de entrenamiento de fuerza y las variables externas en programas de entrenamiento en tenistas competitivos. Considerando los hallazgos del presente estudio, constatamos que la musculación y la pliometría asociadas a los ejercicios específicos de la modalidad (tennis drills) fueron los métodos de entrenamiento de fuerza muscular más eficientes para mejorar las diferentes manifestaciones de fuerza. Nivel de evidencia l; Estudio diagnóstico - Investigación de examen para diagnóstico.

Descriptores: Ejercicio; Rendimiento Atlético; Tenis; Fuerza Muscular.

\section{INTRODUCTION}

In recent decades, the study of strength training has been recognized by the responses in physical capacities, injury prevention, metabolic changes, and others, both in different sports and in health. ' According to Mahn \& Gavião, ${ }^{2}$ strength training in sports develops and maintains muscle strength and should be applied in such a way as to ensure it is transferred at the time of the game.

According to Kovacs, ${ }^{3}$ muscle strength can help tennis players prevent injuries and improve their performance during a match. Strengthening the upper body muscles helps players execute forehand, backhand, volley, smash, and serve strokes, although research focusing on the lower limbs is limited.

According to Euclydes, ${ }^{4}$ explosive strength is the predominant manifestation of strength for the tennis player during a match. Dantas ${ }^{5}$ has established that static strength is used throughout the match when gripping the racket, dynamic strength should be trained to assist in the development of explosive strength, and resistance strength manifests as a basic physical quality and for purposes of injury prevention. More recently, Miranda ${ }^{6}$ noted that the ability to physically withstand a tennis match can become 
difficult as it is necessary to maintain the technical level of the strokes, explosive movements during approach shots and muscle endurance during periods when the players are more active (rallies). Souza ${ }^{7}$ stresses that the importance of rapid strength development lies in maintaining the technical strokes executed by the players over a long period of time, maintaining the speed of the motor action without impairing its execution.

The study conducted by Kovacs et al. ${ }^{8}$ assessed eight young male elite tennis players over five weeks of unstructured and unsupervised training. The results showed a decrease in some biomotor abilities, including muscle power, besides an increase in the rate of fatigue.

Accordingly, we believe that the training of different manifestations of muscle strength in tennis players contributes to the development of speed, agility, acceleration, aerobic and anaerobic endurance. On the other hand, the literature does not present a consensus on the most effective methods carried out with tennis players, considering the external training variables, as well as models of interventionist studies on the effect of changes on physiological and performance response in tennis players.

In this context, the aim of this study was to investigate strength training methods and external variables in training programs in competitive tennis players.

\section{MATERIALS AND METHODS}

Following approval by the institutional review board of Universidade São Judas Tadeu (No. 433566), the systematic literature review was undertaken in the following databases: PubMed, SPORTDiscus and Medline. The selection of articles in the review process followed the descriptors based on DeCS (health sciences descriptors of BIREME). The words "resistance training" and "tennis players" were selected as descriptors. The survey was conducted between March and April 2017. The logical operator "AND" was used to combine the descriptors used to track the publications; the term "tennis players" was supposed to be present in the title of the works while the term " resistance training" and its match terms were supposed to be present in the abstracts of the articles.

The selected articles had to meet the following criteria: keywords in the title and abstract, sample composed of tennis players with more than two years of experience, intervention protocol lasting more than four weeks, written in Portuguese, Spanish and English, and date of publication between 2000 and 2017. The exclusion criteria used were: cross-sectional studies, studies without an adequate description of training variables, article review studies, dissertations, and theses.

Twenty-three potentially eligible publications were selected in the identification phase. After obtaining and subsequently analyzing the articles based on the inclusion and exclusion criteria, only six studies were selected as shown in Figure 1.

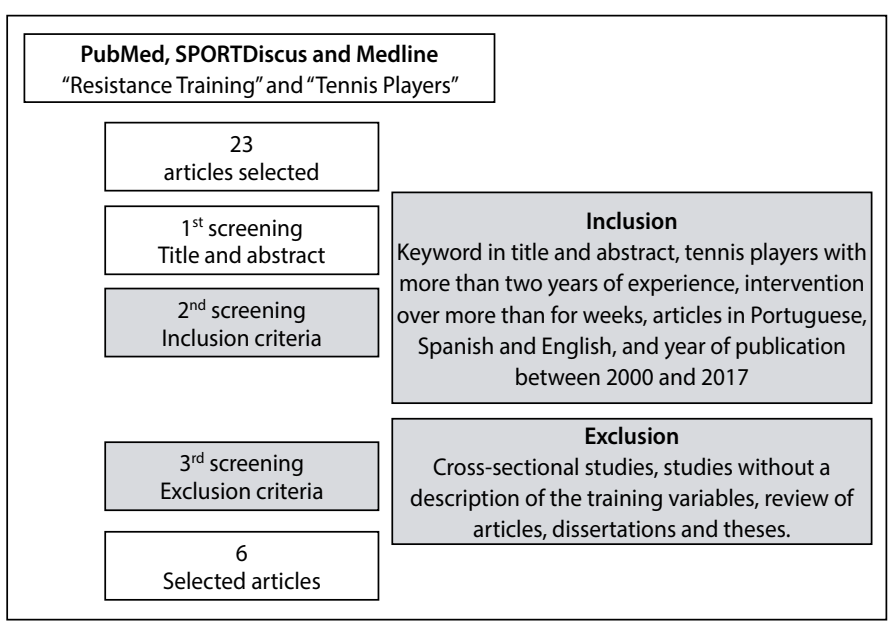

Figure 1. Article selection flowchart.
The studies that met the established criteria were analyzed by researchers, noting down the following variables: 1) year of publication; 2) number of subjects; 3) number of subjects by sex; 4) average age; 5) height; 6) body mass; 7) length of practical/competitive experience; 8) groups; 9) number of subjects per group; 10) training methods used for the intervention; 11) muscle strength training methods; 12) duration of the intervention; 13) weekly frequency, volume per session and load intensity; 14) results of the tests used.

\section{RESULTS}

Table 1 describes the sample characteristics of the studies selected in chronological order of publication, number of subjects; number of subjects by sex; average age; height; body mass; and length of grass court tennis training time.

After all the analysis stages, six articles met the criteria. Articles published as of 2000 evaluated strength in trained individuals. The articles followed an average of $25 \pm 18$ subjects; the research project with the highest subject count totaled 64 people $e^{9}$ and the lowest subject count of 10 people was in the study by Gomes et al. ${ }^{10}$ The distribution of samples between both sexes was observed in $33.3 \%$ of the studies analyzed; ${ }^{11,12}$ exclusively male in 33.3\%; ;,10 and exclusively female (33.3\%) in the studies by Kraemer et al. ${ }^{13}$ and Kraemer et al. ${ }^{14}$ The average age of the participants was $19.0 \pm 2.4$ years, with height and body mass described in 5 studies (83\%). The minimum length of experience in the sport was two years ${ }^{9,11-13}$ and the maximum length was eight years. ${ }^{14}$

Table 2 summarizes the characteristics of the training methods presented in the research projects. Among the research methods, the reviewed articles had an experimental design with pre and post-test randomized groups. Control and experimental groups were found in three of the studies, $9,13,14$ while only an experimental group was found in the others. ${ }^{10-12}$ We observed 10 different training types involving weight training and plyometrics present in $83 \%$ of the studies, and only Maffiuletti et al. ${ }^{12}$ used electrostimulation as a muscle strength training method. Specific technical and tactical training (tennis drills) was present in $100 \%$ of the works reviewed. All the works demonstrate improvement of physical capacities, muscle strength and specific

Table 1. Characteristics of number, sex, body composition and length of training of subjects described in the studies.

\begin{tabular}{|c|c|c|c|c|c|c|c|c|}
\hline Authors & Year & $n$ & $\hat{0}$ & o & $\begin{array}{c}\text { Age } \\
\text { (years) }\end{array}$ & $\begin{array}{l}\text { Height } \\
(\mathrm{cm})\end{array}$ & $\begin{array}{c}\text { Body mass } \\
(\mathrm{Kg})\end{array}$ & $\begin{array}{l}\text { Length of } \\
\text { training } \\
\text { (years) }\end{array}$ \\
\hline $\begin{array}{l}\text { Salonikidis; } \\
\text { Zafeiridis }^{9}\end{array}$ & 2008 & 64 & 64 & 0 & $21.1 \pm 1.3$ & $174 \pm 0.09$ & $71.7 \pm 13.1$ & 2 to 3 \\
\hline Gomes et al. ${ }^{10}$ & 2013 & 10 & 10 & 0 & $18.5 \pm 0.4$ & $178 \pm 4$ & $72.4 \pm 6$ & $>5$ \\
\hline $\begin{array}{c}\text { Barber-Westin } \\
\text { et al. }{ }^{11}\end{array}$ & 2010 & 15 & 5 & 10 & $13 \pm 1.5$ & NA & NA & $\geq 2$ \\
\hline Maffiuletti et al. ${ }^{12}$ & 2009 & 12 & 5 & 7 & $23 \pm 3$ & $171 \pm 7$ & $63 \pm 8$ & $>2$ \\
\hline \multirow[t]{3}{*}{ Kraemer et al..$^{13}$} & 2000 & 24 & 0 & 8 & $19.8 \pm 1.7$ & $167 \pm 5.1$ & $58.9 \pm 7.8$ & 2.4 \\
\hline & & & 0 & 8 & $19.0 \pm 0.9$ & $168 \pm 4.2$ & $60.4 \pm 7.6$ & \\
\hline & & & 0 & 8 & $18.9 \pm 1.2$ & $167.5 \pm 5.2$ & $60.8 \pm 7.7$ & \\
\hline \multirow[t]{3}{*}{ Kraemer et al. ${ }^{14}$} & 2003 & 27 & 0 & 9 & $19.2 \pm 1.1$ & $167.9 \pm 5.6$ & $60.5 \pm 7.7$ & 8.1 \\
\hline & & & 0 & 10 & $18.6 \pm 1.3$ & $167 \pm 4.1$ & $60.8 \pm 7.8$ & \\
\hline & & & 0 & 8 & $19.3 \pm 1.6$ & $167.3 \pm 6.1$ & $60.1 \pm 7.6$ & \\
\hline
\end{tabular}


Table 2. Methodological characteristics, strength training methods and physical fitness variables in competitive tennis players.

\begin{tabular}{|c|c|c|c|c|c|c|}
\hline Authors & Groups & $\mathbf{N}$ & Training methods (exercises) & $\begin{array}{l}\text { Study duration } \\
\text { (no. of weeks) }\end{array}$ & $\begin{array}{l}\text { Weekly frequency } \\
\text { (sessions per week) }\end{array}$ & $\begin{array}{l}\text { Session duration } \\
\text { (minutes) }\end{array}$ \\
\hline \multirow[t]{3}{*}{ Kraemer et al. ${ }^{13}$} & Control & 8 & Tennis Drills & 36 & 2 or 3 & 90 \\
\hline & Periodized & 8 & Strength training + Tennis Drills & 36 & 2 to 3 & 90 \\
\hline & Circuit & 8 & Strength training circuit & 36 & 2 to 3 & 90 \\
\hline \multirow[t]{3}{*}{ Kraemer et al. ${ }^{14}$} & Periodized & 9 & Strength training + Tennis Drills & 36 & 3 & NA \\
\hline & Non-periodized & 10 & Strength training + Tennis Drills & 36 & 3 & NA \\
\hline & Control & 8 & Specific tennis exercises & 36 & 3 & NA \\
\hline \multirow[t]{4}{*}{ Salonikidis;Zafeiridis ${ }^{9}$} & Control & 16 & No intervention & 9 & 3 & $x$ \\
\hline & Plyometrics & 16 & Plyometric Exercises & 9 & 3 & 120 \\
\hline & Tennis Drills & 16 & Specific tennis exercises & 9 & 3 & 120 \\
\hline & Combined Training & 16 & Plyometrics + Tennis Drills & 9 & 3 & 120 \\
\hline Maffiuletti et al. ${ }^{12}$ & Experimental & 12 & Electrostimulation + tennis training & 7 & 3 & 16 \\
\hline Barber-Westin et al. ${ }^{11}$ & Experimental & 15 & $\begin{array}{l}\text { Plyometrics / Strength Training / } \\
\text { Power / Flexibility / Tennis Drills }\end{array}$ & 6 & 3 & 90 \\
\hline Gomes et al. ${ }^{10}$ & Experimental & 10 & $\begin{array}{l}\text { Resistance/ strength training / } \\
\text { Agility / Speed / Tennis Drills }\end{array}$ & 5 & 3 to 4 & NA \\
\hline
\end{tabular}

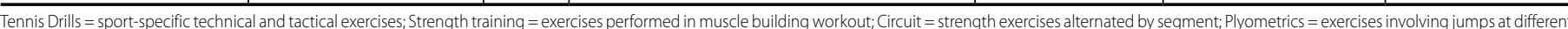
heights and in different directions; Electrostimulation = electrical stimulation on the quadriceps muscles; NA = not available.

technical skills of the sport. The duration ranged from 5 to 36 weeks with an average of $16 \pm 13$ weeks of training. Weekly frequency was between two and four sessions. The duration of each session was described in four studies (67\%), ranging from 16 to 120 minutes. The study by Gomes et al. ${ }^{10}$ and Kraemer et al. ${ }^{14}$ did not report the duration of the physical training sessions.

Table 3 presents the characteristics of the training protocols used in the studies. When muscle building workout was used as a training method, the intensity was established by the number of repetitions maximum (RM). In the case of plyometric training the intensity was controlled by the number of jumps and/or exercise duration. In the electrical stimulation protocol, intensity was controlled by stimulus duration and the number of repetitions. Intervals varied according to the training methods used and were mentioned in $67 \%$ of the reviewed studies. Strength training zone by RM prescribed ranged from 4 to 20 repetitions.

Table 4 presents the results of the studies, demonstrating an improvement in the body composition of the tennis players after intervention in two studies (33\%). Three studies (50\%) showed that the intervention improved serve speed, agility of technical shots played from the back of the court, and the serve speed. Three references (50\%) showed improvement in aerobic and anaerobic power. The acceleration speed described as the ability to accelerate the body in the shortest possible time improved in two studies (33\%). On the other hand, lower limb explosive strength improved in five (83\%) studies and maximal strength (1RM) in 67\%.

\section{DISCUSSION}

This systematic review discusses physical strength training methods in tennis players. The methods used most frequently were: muscle building workout, plyometrics or electrostimulation, as they were present in all programs aimed at improving fitness levels in competitive tennis players. Thus we emphasize that: a) publications on the subject occurred as of 2000; b) the studies presented interventions with more than five weeks of training; $c$ ) all the tennis players were competitors and had been playing for at least two years; d) strength training was present through one method or another in all the works.

Although strength training is recommended as the basis for training in various sports, in regards to grass court tennis, 3,15 there is no consistency of the best training methods, of training associated
Table 3. Characteristics of the exercise protocols, number of sets, number of repetitions and intervals between sets.

\begin{tabular}{|c|c|c|c|c|}
\hline Authors & Exercises & $\begin{array}{l}\text { Number } \\
\text { of Sets }\end{array}$ & $\begin{array}{l}\text { Number of } \\
\text { Repetitions }\end{array}$ & $\begin{array}{c}\text { Interval } \\
\text { between Sets }\end{array}$ \\
\hline \multirow[t]{3}{*}{ Kraemer et al. ${ }^{13}$} & Tennis Drills & NA & NA & NA \\
\hline & $\begin{array}{c}\text { Muscle building } \\
\text { workout }\end{array}$ & 2 to 4 & $\begin{array}{l}4 \text { to } 6 \mathrm{RM} / \\
8 \text { to } 10 \mathrm{RM} / \\
12 \text { to } 15 \mathrm{RM}\end{array}$ & NA \\
\hline & Circuit & 1 (circuit) & 8 to $10 \mathrm{RM}$ & NA \\
\hline \multirow[t]{3}{*}{ Kraemer et al. ${ }^{14}$} & $\begin{array}{c}\text { Muscle building } \\
\text { workout }\end{array}$ & 3 & $\begin{array}{l}4 \text { to } 6 \mathrm{RM} / \\
8 \text { to } 10 \mathrm{RM} / \\
12 \text { to } 15 \mathrm{RM}\end{array}$ & $1^{\prime} 30^{\prime \prime}$ to $3^{\prime}$ \\
\hline & $\begin{array}{c}\text { Muscle building } \\
\text { workout }\end{array}$ & 3 & 8 to $10 \mathrm{RM}$ & $1^{\prime} 30^{\prime \prime}$ to $2^{\prime}$ \\
\hline & Tennis Drills & NA & NA & NA \\
\hline \multirow[t]{4}{*}{$\begin{array}{l}\text { Salonikidis; } \\
\text { Zafeiridis }^{9}\end{array}$} & Control & $x$ & $x$ & $x$ \\
\hline & 4 (plyometrics) & 2 & NA & $3^{\prime}$ to $4^{\prime}$ \\
\hline & 4 (tennis drills) & NA & 8 & NA \\
\hline & $\begin{array}{l}2 \text { (plyometrics) } \\
+2 \text { (drills) }\end{array}$ & NA & NA & NA \\
\hline Maffiuletti et al. ${ }^{12}$ & Leg extension & $\begin{array}{c}1 \text { (isometric } \\
\text { exercise) }\end{array}$ & $20\left(4^{\prime \prime}\right)$ & $25^{\prime \prime}$ \\
\hline $\begin{array}{l}\text { Barber-Westin } \\
\text { et al. }{ }^{11}\end{array}$ & Miscellaneous & 2 to 3 & 6 to 20 & NA \\
\hline Gomes et al. ${ }^{10}$ & Miscellaneous & $\begin{array}{l}15 \text { to } 28 \\
\text { total }\end{array}$ & 6 to 20 & $1^{\prime}$ to $3^{\prime}$ \\
\hline
\end{tabular}

Tennis Drills = sport-specific technical and tactical exercises: Circuit = strength exercises alternated by segment; Plyometrics $=$ exercises involving jumps at different heights and in different directions; RM = repetitions maximum; $\mathrm{NA}=$ not available.

with external loads. Therefore, this review demonstrated the role of strength training in tennis players, its methods and the most commonly prescribed exercises.

We found few studies analyzing the effects of strength training applied to tennis players in the last 14 years, despite the fact that the sport is popular worldwide, with 205 nations affiliated to the International Tennis Federation (ITF) and 25 million players in the United States alone. ${ }^{16}$ 
Table 4. Results of the interventions of the reviewed studies.

\begin{tabular}{|c|c|c|}
\hline Authors & Groups & Results \\
\hline \multirow[t]{4}{*}{ Kraemer et al. ${ }^{13}$} & Control & $x$ \\
\hline & Periodized & $\uparrow$ Fat-free Mass; $\downarrow$ Fat \%; $\uparrow$ anaerobic power; \\
\hline & & $\uparrow$ vertical jump; $\uparrow 1 \mathrm{RM} ; \uparrow$ serve speed \\
\hline & Circuit & $\uparrow 1 \mathrm{RM}$ \\
\hline \multirow[t]{3}{*}{ Kraemer et al. ${ }^{14}$} & Periodized & $\begin{array}{c}\uparrow \text { fat-free mass; } \downarrow \text { Fat } \% \text {; } \downarrow \text { of aerobic power; } \\
\uparrow \text { anaerobic power; } \uparrow \text { vertical thrust; } \uparrow \\
1 \mathrm{RM} ; \uparrow \text { speed of technical strokes }\end{array}$ \\
\hline & Non- periodized & $\begin{array}{c}\uparrow \text { fat-free mass; } \downarrow \text { Fat } \% \text {; } \downarrow \text { of aerobic power; } \\
\uparrow \text { anaerobic power; } \uparrow \text { vertical thrust; } \uparrow \\
1 \mathrm{RM} ; \uparrow \text { speed of technical strokes }\end{array}$ \\
\hline & Control & $x$ \\
\hline \multirow[t]{4}{*}{$\begin{array}{l}\text { Salonikidis; } \\
\text { Zafeiridis }^{9}\end{array}$} & Control & $x$ \\
\hline & Plyometrics & $\begin{array}{l}\uparrow \text { reaction time; } \uparrow 4 \mathrm{~m} \text { sprint; } \uparrow \text { lower } \\
\quad \text { limb power; } \uparrow \text { maximal strength }\end{array}$ \\
\hline & Tennis Drills & $\uparrow 4 \mathrm{~m}$ sprint; $\uparrow 12 \mathrm{~m}$ sprint; $\uparrow$ lower limb power; \\
\hline & $\begin{array}{l}\text { Plyometrics } \\
+ \text { Drills }\end{array}$ & $\begin{array}{l}\uparrow \text { reaction time; } \uparrow 4 \mathrm{~m} \text { sprint; } \uparrow 12 \mathrm{~m} \text { sprint; } \\
\uparrow \text { lower limb power; } \uparrow \text { maximal strength }\end{array}$ \\
\hline $\begin{array}{l}\text { Maffiuletti } \\
\text { et al. }{ }^{12}\end{array}$ & Experimental & $\begin{array}{l}\uparrow \text { of strength in } \mathrm{CMJ} \text {; improvement } \\
\text { in speed at } 10 \text { meters }\end{array}$ \\
\hline $\begin{array}{c}\text { Barber-Westin } \\
\text { et al. }{ }^{11}\end{array}$ & Experimental & $\begin{array}{l}\uparrow \text { triple jump; } \uparrow \text { agility of strokes; } \uparrow \\
\text { agility of serve; } \uparrow \text { suicide test }\end{array}$ \\
\hline Gomes et al. ${ }^{10}$ & Experimental & $\uparrow 1 \mathrm{RM} ; \uparrow$ aerobic resistance; improvement in agility \\
\hline
\end{tabular}

The sport enjoys widespread visibility through television broadcasts, and features in the Olympics (since 1988 in Seoul) and annually in the four Grand Slams (Australian Open, Roland Garros, Wimbledon and US Open). ${ }^{17}$ These aspects appear to contribute to the number of training centers around the world, attracting professionals from different areas to work on the preparation of new athletes. In many cases at competitive training centers, with less infrastructure and fewer human resources, training is the responsibility of the coach/teacher, which allows us to hypothesize that this particular study can contribute to the organization of strength training in these professionals.

Regarding the profile of sample groups in the reviewed studies, we noticed that they were made up of male and female adolescents and adults, with at least two years of competitive experience. In recent years there has been an increase in the competitive longevity of tennis players, which could explain the need to develop research projects with experienced tennis players, as strength exercises are known to play an important role in maintaining lean mass, preventing injuries and maintaining body fat percentages.

Considering that tennis is an acyclic sport, the training methods found were effective in developing muscle strength. Due to the demands of the sport, studies presented exercises for the development of agility, speed, anaerobic and aerobic power and flexibility. On the other hand, all the reviewed articles used the plyometric method of muscle strength training as well as weight training. Such methods are suggested by other studies $^{3,15}$ to improve performance in tennis players.

Kraemer et al. ${ }^{13}$ conducted a study with 24 female tennis players divided into three groups with 8 players in each. The group that participated in the periodized training (36 weeks) exhibited an increase in fat-free mass and a decrease in body fat \% in comparison to the control group and the non-periodized group (circuit). The same author, ${ }^{14}$ using the same training and evaluation protocol, found a significant decrease in body fat percentage (Periodized Group - pre $22.9 \pm 3.9$ vs. post $19.1 \pm 3.6 \%$ ) vs. (Non-Periodized Group - pre $23.7 \pm$ 4.9 vs. post $21.6 \pm 2.9 \%$ ); fat-free mass (Periodized Group - pre vs. $46.5 \pm$ 4.9 vs. post $49.8 \pm 4.9 \mathrm{~kg}$ ) vs. (Non-Periodized Group - pre $46.1 \pm 4.0$ vs. post $47.7 \pm 4.8 \%)$ at 36 weeks of training. The somatotype and body composition of 123 elite male and female junior tennis players were established by Sánchez-Muñoz et al. ${ }^{18}$ The results showed that the girls experienced a variation in fat percentage $(\triangle 22.2-34.4 \%)$ and lean body mass ( $\triangle 42.9-48.7 \mathrm{~kg}$ ), similar to the studies reviewed in this particular article. Ziemann et al. ${ }^{19}$ investigated the body composition of 17 tennis players aged 15-17 years who appeared in the International Tennis Federation's Junior Circuit Ranking (ITFJC), finding means similar to the studies mentioned, with a fat percentage of $21.0 \pm 5.0 \%$ and fat-free mass of $45.1 \pm 4.1 \mathrm{~kg}$.

Anaerobic and aerobic power was observed in $67 \%$ of the studies, with special emphasis on the research project undertaken by Kraemer et al., ${ }^{13}$ in which anaerobic power was evaluated by the Wingate test, showing improvement in the group that had undergone strength training and tennis drills. In the work of Barber-Westin et al., ${ }^{11}$ anaerobic power was measured indirectly on the court using the Suicide Test, in which the players were instructed to cover a distance of 46.6 meters, running in a zig-zag pattern between the tennis court lines in the shortest possible time. Significant improvement was observed Pre and Post training (100 \pm 15.3 vs. $90.3 \pm 10 \mathrm{sec})$ at the end of the 6 weeks of physical training. The study by Gomes et al..$^{10}$ demonstrated an increase in the distance covered (pre vs. post $894.4 \pm 241.4$ vs. $1104.4 \pm 363.0 \mathrm{~m}$ ) after 5 weeks of physical training using the Yo-Yo Intermittent Endurance Test. Kraemer et al. ${ }_{1}{ }^{14}$ who assessed anaerobic and aerobic power using the Wingate and treadmill ergospirometry tests in female tennis players, observed a significant increase in anaerobic power in the periodized group with strength training combined with tennis drills (pre vs. post $624 \pm 130$ vs. $699 \pm 95 \mathrm{~W}$ ), and in the non-periodized group that used the same training methods (pre vs. post $563 \pm 116$ vs. $664 \pm 124 \mathrm{~W}$ ). However, $V \mathrm{O}_{2 \max }$ decreased significantly in both groups after 9 months of training (Periodized Group - pre vs. post $49.4 \pm 4.4$ vs. $45.7 \pm 5.2 \mathrm{~mL} / \mathrm{kg} / \mathrm{min}$ ) vs. (NonPeriodized Group - pre vs. post $51.0 \pm 3.2$ vs. $45.1 \pm 4.9 \mathrm{~mL} / \mathrm{kg} / \mathrm{min})$, suggesting that this decrease was due to the fact that the contested shots occurred over a short period of time, requiring high demand at peak anaerobic power.

Kovacs $^{20}$ mentions means between 44 and $69 \mathrm{~mL} / \mathrm{kg} / \mathrm{min}$ in the $\mathrm{VO}_{2 \max }$ of elite competitive tennis players, corroborating the values found in the reviewed studies. Despite the decrease in maximal aerobic power in the study by Kraemer et al., ${ }^{14}$ Kovacs $^{3}$ and Miranda ${ }^{6}$ stress the importance of this capacity for recovery between points and recovery between matches that are held on a daily basis.

Displacement speed is an essential condition in the performance of tennis players, and was analyzed in $67 \%$ of the reviewed studies. The work of Barber-Westin et al. ${ }^{11}$ evaluated the acyclic response of the sport based on forehand and backhand technical shots by calculating the repetition of movements over 30 seconds of execution. A significant increase in the number of repetitions (pre vs. post $8.1 \pm 1.0$ vs. $9.0 \pm 0.7$ repetitions) was shown after physical training. Maffiuletti et al. ${ }^{12}$ evaluated acceleration in the 10-meter running test in tennis players of both sexes, observing a significant decrease of 3.3\% in time after 7 weeks of strength training using the electrostimulation method in combination with tennis drills.

The study by Gomes ${ }^{10}$ evaluated agility using the T-Test at a distance of 40 meters with changes of direction, observing a significant decrease in the time taken to cover the distance (pre $9.99 \pm 0.49$ vs. 
post $9.45 \pm 0.47 \mathrm{sec}$ ) after 5 weeks of physical training. Salonikidis and Zafeirides ${ }^{9}$ evaluated different manifestations of speed in male tennis players divided into 4 groups. With the exception of the control group, all groups undergoing plyometric training significantly improved their reaction time (pre $221 \pm 35$ vs. post $162 \pm 32 \mathrm{~ms}$ ); 4-meter sprint (pre $1.58 \pm 0.17 v$ v. post $1.44 \pm 0.16 \mathrm{sec}$ ). On the other hand, the group that trained only tennis drills improved their sprint in the 4-meter run (pre $1.60 \pm 0.15$ vs. post $1.45 \pm 0.14 \mathrm{sec}$ ) and 12-meter run (pre $2.46 \pm$ 0.19 vs. post $2.42 \pm 0.18 \mathrm{sec}$ ); the group that combined plyometrics with tennis drills achieved a significant improvement in reaction time (pre $222 \pm 71$ vs. post $158 \pm 36 \mathrm{~ms}$ ), 4-meter sprint (pre $1.57 \pm$ 0.21 vs. post $1.47 \pm 0.17 \mathrm{sec}$ ) and 12-meter sprint (pre $2.47 \pm 0.19 \mathrm{vs}$. post $2.41 \pm 0.19 \mathrm{sec}$ ).

Kovacs $^{3}$ emphasizes that tennis players need to improve their reaction time, acceleration in multidirectional movements due to the complexity of the sport, in which the player cannot predict their opponent's strategy or which decision they will make. Thus, the author suggests that speed training be implemented with specific movements in sprints, not exceeding a distance of 20 meters.

The different manifestations of muscle strength were evaluated in the reviewed studies, demonstrating the importance of this functional capacity in the performance of tennis players of both sexes. Kraemer et al. ${ }^{13}$ discovered an improvement in maximal strength in the 1RM test in the group that underwent periodized training with loads in 4-6RM, 8-10RM and 12-15RM repetition zones, and in the group that used a circuit of muscle building workout with loads in the zone between 8 and 10RM. However, the group undergoing periodized training had improved lower limb explosive strength in the vertical thrust test.

The study by Barber-Westin et al. ${ }^{11}$ combined plyometric training with muscle building workout in 2 and 3 sets, with 6 to 20 repetitions, observing an improvement in lower limb muscle power (pre 330.4 \pm 71.7 vs. post $366.7 \pm 59.8 \mathrm{~cm}$ ). Maffiuletti et al. ${ }^{12}$ conducted the only study with electrostimulation and exercise in the leg extension machine with 1 set consisting of 20 isometric contractions lasting 4 seconds each, showing a $6.4 \%$ increase in lower limb power, although the authors indicate that a weekly session of electrostimulation can aid in the transfer of elastic energy in the stretching-shortening cycle of explosive force production in tennis players.

Gomes et al. ${ }^{10}$ conducted periodized strength training over 5 weeks using resistance strength (21 sets, 15 to 20 repetitions and 60\% 1RM load, with a 1-minute interval between sets) in the first week; dynamic strength (28 sets, 12 repetitions and a 70\% 1RM load with a 2-minute interval between sets) in the second week, and explosive strength (15 to 25 sets, 6 repetitions with intensity of 30-50\% 1RM, and a 3-minute interval between sets) from the third to the fifth week. A significant increase in maximal bench press strength (pre $74.3 \pm 16.3$ vs. post $81.0 \pm$ $17.7 \mathrm{~kg}$ ) and leg press strength (pre $454.4 \pm 78.9$ vs. post $507.8 \pm 88.9 \mathrm{~kg}$ ), without an impact on explosive strength, was observed.

Kraemer et al. ${ }^{14}$ used muscle building workout as a physical training method with three sets and loads in repetition zones 4 to 6RM, 8 to 10RM and 12 to 15RM in the periodized group, and 3 sets and repetition zone 8 to 10RM in the non-periodized group. Both groups achieved a significant increase in maximal strength (1RM) in Leg Press (Periodized Group - 19\%) vs. (Non-Periodized Group - 17\%), bench press (Periodized Group - 23\%) vs. (Non-Periodized Group - 17\%), shoulder development (Periodized Group - 24\%) vs. (Non-Periodized Group - 23\%), and lower limb power based on vertical jump (Periodized Group - 50\%) vs. (Non-Periodized Group - 37\%), with significant intergroup difference. The third group of the study, which trained only tennis drills, did not achieve any improvement in these manifestations of strength during the nine months of training.

Salonikidis and Zafeirides ${ }^{9}$ observed a significant increase in explosive strength in the group undergoing plyometric training (pre $13.6 \pm 4.4$ vs. post $18.3 \pm 6.1 \mathrm{~cm}$ ); in the group that performed only tennis drills (pre $12.7 \pm 3.8$ vs. post $14.9 \pm 3.6 \mathrm{~cm}$ ), and in the group that combined plyometrics with tennis drills (pre $13.8 \pm 5.5$ vs. post $16.9 \pm 4.8 \mathrm{~cm}$ ). The results demonstrated that the group that trained plyometrics (pre $950 \pm 269$ vs. post $1056 \pm 313 \mathrm{~N}$ ) and plyometrics in combination with tennis drills (pre $886 \pm 419$ vs. post $965 \pm 385 \mathrm{~N}$ ) increased their maximal isometric force on the force plate applied in the leg press exercise. In this study, the external training load was poorly detailed.

Strength training has been suggested ${ }^{3,15}$ as a means of preventing and reducing joint, tendon and ligament injuries in tennis players. Special emphasis is placed on the importance of strengthening the shoulder girdle muscles to endure the demand for repetitive movements executed with a high demand for muscle power. Thus, training for tennis players should include exercises specifically designed for this region, emphasizing both concentric and eccentric actions. Lower body strengthening is also recommended ${ }^{3}$ as this part of the body is affected by injuries. In this context, bilateral and unilateral exercises should be introduced in the strength training of high performance tennis players.

Reid et al. ${ }^{15}$ suggest a periodized strength training program for elite junior tennis players divided into four blocks. The first block was organized with exercises in all planes of motion including pelvic and shoulder girdle stabilization (prescription between 50 and 75\% 1RM, 10-12 exercises, 3 sets, 8-12 repetitions and weekly frequency between 3 and 4 sessions). It is suggested that strength training be developed based on this regimen using general (muscle building workout) and specific (plyometric) training methods.

Thus, this particular review did not enable us to clearly determine which volume and intensity indicators would be appropriate in strength training programs according to sex, age, level of physical and technical fitness in tennis players. Further studies are needed in the organization of the act of prescribing strength training in competitive grass court tennis players.

\section{CONCLUSIONS}

This article has highlighted evidence of the methods and results of prescribing strength training in competitive tennis players. So far, physical training programs that have combined different strength training methods with tennis-specific training (tennis drills), have demonstrated greater effectiveness in increasing physical abilities related to the sport. Accordingly, based on the analysis of the 6 reviewed studies, we can conclude that muscle building workout and plyometrics combined with technical and tactical exercises specifically intended for the sport (tennis drills) were the muscle strength training methods that proved most efficient at improving the different manifestations of strength.

\section{ACKNOWLEDGMENTS}

The authors are grateful to CAPES (Higher Education Personnel Upskilling Coordination Office) for their financial support allocated to MIRANDA JMQ and RICA RL. The support did not influence the decision to publish or the preparation of the article.

All authors declare no potential conflict of interest related to this article 
AUTHORS' CONTRIBUTIONS: Each author made significant individual contributions to this manuscript. JMQM and AFJ: were the main contributors in the intellectual conception of the study. LFTP and RLR: data collection and analysis, development of the text of the article. MLM and DSB: review of results and writing of the manuscript.

\section{REFERENCES}

1. Paiva RS. Treinamento de força nos desportos - fatores intervenientes e novas perspectivas. Rev Trein Desp. 2007;8(1):34-9.

2. Mahn PA, Gavião MB. A influência do treinamento resistido em atletas de tênis de campo. Rev Bras Cienc Saude. 2010;8(24):3-7.

3. Kovacs MS. Applied physiology of tennis performance. Br J Sports Med. 2006;40(5):381-6.

4. Euclydes PT, Dantas EH, Marins JCB, Pinto JA. Qualidades físicas intervenientes e seu grau de importância no tênis de campo. Rev Min Educ Fis. 2005;13(1):7-27.

5. Dantas EHM. A prática da preparação física. 5. ed. Rio de Janeiro: Sprint, 2003.

6. Miranda JM. O jogo de tênis e suas implicações energéticas. Sci Health. 2011;2(3):177-80.

7. Souza RJ. Treinamento de força rápida aplicado na preparação física de jovens tenistas. Int Sci Place. 2010;3(14):37-56

8. Kovacs MS, Pritchett R, Wickwire PJ, Green JM, Bishop P. Physical performance changes after unsupervised training during the autumn/spring semester break in competitive tennis players. Br J Sports Med 2007;41:705-710

9. Salonikidis K, Zafeiridis A. The effects of plyometric, tennis-drills, and combined training on reaction, lateral and linear speed, power, and strength in novice tennis players. J Strength Cond Res. 2008;22(1):182-91.

10. Gomes RV, Moreira A, Lodo L, Nosaka K, Coutts AJ, Aoki MS. Monitoring Traning loads, stress, immuneendocrine responses and performance in Tennis Players. Biol Sport. 2013;30(3):173-80.
11. Barber-Westin SD, Hermeto AA, Noyes FR. A six-weeks neuromuscular training program for competitive junior tennis players. J Strength Cond Res. 2010; 24(9):2372-82.

12. Maffiuletti NA, Bramanti J, Jubeau M, Bizzini M, Deley G, Cometti G. Feasibility and efficacy of progressive electrostimulation in tennis players. J Strength Cond Res. 2009;23(2):677-82.

13. Kraemer WJ, Ratamess N, Fry AC, Triplett-McBride T, Koziris LP, Bauer JA, et al. Influence of resistance training volume and periodization on physiological and performance adaptations in collegiate woman tennis players. Am J Sports Med. 2000;28(5):626-33.

14. KraemerWJ, Hakkinen $K$, Triplett-Mcbride NT, Fry AC, Koziris LP, Ratamess NA, et al. Physiological changes with periodized resistance training in women Tennis Players. Med Sci Sports Exerc. 2003;35(1):157-68.

15. Reid M, Quinlan G, Kearney S, Jones D. Planning and Periodization for the Elite Junior Tennis Player. Streng Condit Journal. 2009;31(4):69-76

16. Turner MS, Pluim BM. Anyone for tennis? Br J Sports Med. 2007;41(11):701-2.

17. Gillmeister H. Tennis History. ITF Coach Sport Sci Review. 2008;15(46):16-8.

18. Sánchez-Muñoz C, Sanz D, Zabala M. Anthropometric characteristics, body composition and somatotype of elite junior tennis players. Br J Sports Med. 2007;41(11):793-9.

19. Ziemann E, Sledziewska E, GrzywaczT, Gibson AL, Wierzba TH. Body composition and physical capacity of elite adolescent female tennis players. Georgian Med News. 2011;(196-197):19-26.

20. Kovacs MS. Tennis physiology training the competitive athlete. Sports Med. 2007;37(3):189-98. 